\title{
Diez años de la convención sobre patrimonio inmaterial confirman su validez y necesaria revisión constante
}

"Desde su aprobación en octubre de 2003 hasta la presentación de los primeros informes periódicos en 2011 y 2012, la Convención para la Salvaguardia del Patrimonio Cultural Inmaterial ha dado muchos pasos, tanto a nivel internacional como nacional. El décimo aniversario de la Convención ofrece a una amplia gama de actores la oportunidad de hacer un primer balance y analizar los principales desafíos, limitaciones y posibilidades en relación con su aplicación". Con estas palabras introduce la web de la UNESCO el apartado dedicado al décimo aniversario (2003-2013) de la Convención. En revista ph no hemos querido dejar pasar esta conmemoración para aportar algunos elementos de reflexión a este balance. Para ello, hemos contado con Elisa de Cabo de la Vega, subdirectora general de Protección del Patrimonio Histórico de la Secretaría de Estado de Cultura.

Elisa de Cabo de la Vega | subdirectora general de Protección del Patrimonio Histórico, Secretaría de Estado de Cultura y miembro de la delegación española de la Convención de la UNESCO

URL de la contribución <www.iaph.es/revistaph/index.php/revistaph/article/view/3388>

La Convención para la Salvaguardia del Patrimonio Cultural Inmaterial se aprobó por la Asamblea General de la UNESCO y, tras haber obtenido la ratificación de 30 países, entró en vigor el 20 de abril de 2006. De ello se desprende que el proceso de ratificación fue de una celeridad excepcional y demuestra, por tanto, el interés de los Estados en la protección de este patrimonio. Actualmente son 153 los países que la han ratificado.

En todo caso, la Convención requería un desarrollo para su puesta en práctica, ya que había muchos temas que no quedaban resueltos. Para ello, se realizaron una serie de encuentros y reuniones internacionales que dieron lugar a la elaboración de las denominadas Directrices Operativas, aprobadas en la segunda Asamblea de la UNESCO (celebrada entre el 16 y 19 de junio de 2008) y posteriormente modificadas en junio de 2010.

Pues bien, volviendo a la Convención, es en el Preámbulo donde se recoge toda su filosofía. En este apartado se pone de manifiesto que se trata de un instrumento jurídico fundamentado en la Declaración Universal de los Derechos Humanos y que surge con la finalidad de solventar las repercusiones adversas de la mundialización, especialmente para las minorías y los pueblos indígenas. Se reconoce su función de intercambio y entendi- miento entre los seres humanos, y que las comunidades (en especial las indígenas), los grupos y los individuos son los principales agentes en la conservación y mantenimiento de este patrimonio.

Es precisamente el tema de la conservación y salvaguardia uno de los aspectos fundamentales de la Convención. Dentro de las medidas internacionales se opta por crear la Lista Representativa de Patrimonio Cultural Inmaterial y la Lista de Medidas Urgentes de Salvaguardia (mecanismos que estaban previstos en la Convención sobre Patrimonio Mundial Cultural y Natural de 1972), así como los Proyectos de Buenas Prácticas y la Asistencia Internacional. En el desarrollo de estos mecanismos a lo largo de los últimos años es donde vamos a centrar nuestro análisis.

La Lista Representativa de Patrimonio Cultural Inmaterial ha sido el instrumento más utilizado por parte de los Estados. Sin embargo, el hecho de que no hubiera límite en cuanto al número de candidaturas por país ha dado lugar a que sea una Lista "representativa" sólo de algunos Estados, es decir, desequilibrada geográficamente. Así, mientras que en Europa hay 85 manifestaciones y en Asia 103, nos encontramos que en América Latina y el Caribe hay 38 y en África 18. 
Debido a esta situación y al elevado número de candidaturas que se han ido presentando en cada ciclo, con las consiguientes dificultades de gestión por parte de la Secretaría de la Convención, así como para emitir las adecuadas recomendaciones por parte del Órgano Subsidiario y las consiguientes evaluaciones por parte del Comité de Patrimonio Cultural Inmaterial, en la reunión de dicho Comité de 2011, se estableció la decisión de procurar examinar al menos un expediente por Estado, estableciéndose además un tope global por año. Al mismo tiempo, se establecía la siguiente priorización:

- En primer lugar se evaluarán las candidaturas y proyectos de aquellos Estados que no tienen ningún proyecto de buenas prácticas o elementos inscritos en la Lista Representativa de Patrimonio Cultural Inmaterial o de Salvaguardia Urgente.

- Las candidaturas multinacionales.

- Estados que tengan menor número de candidaturas o proyectos inscritos.

El hecho de que los Estados se hayan "lanzado" a inscribir candidaturas ha demostrado, por un lado, el interés que ha suscitado el patrimonio cultural inmaterial y conlleva el que haya mejorado notablemente su protección, tanto a través de las legislación como de los inventarios (es un requisito indispensable para la inscripción en las listas); pero, por otro lado, hay que advertir del riesgo que puede suponer una mayor sensibilización del patrimonio ya que, como dice el art. 102 de las directrices operativas de la Convención, "las medidas de sensibilización no pueden descontextualizar, desnaturalizar, o dañar la imagen del patrimonio inmaterial".

En cuanto a la Lista de Salvaguardia Urgente y Proyectos de Buenas Prácticas, han sido utilizados, significativamente, en menor medida por parte de los Estados. Así tan sólo hay 31 manifestaciones inscritas en la Lista de Salvaguardia Urgente y 10 Proyectos de Buenas Prácticas.

Mención especial merece el funcionamiento de la Asistencia Internacional, previsto en los párrafos 47 y

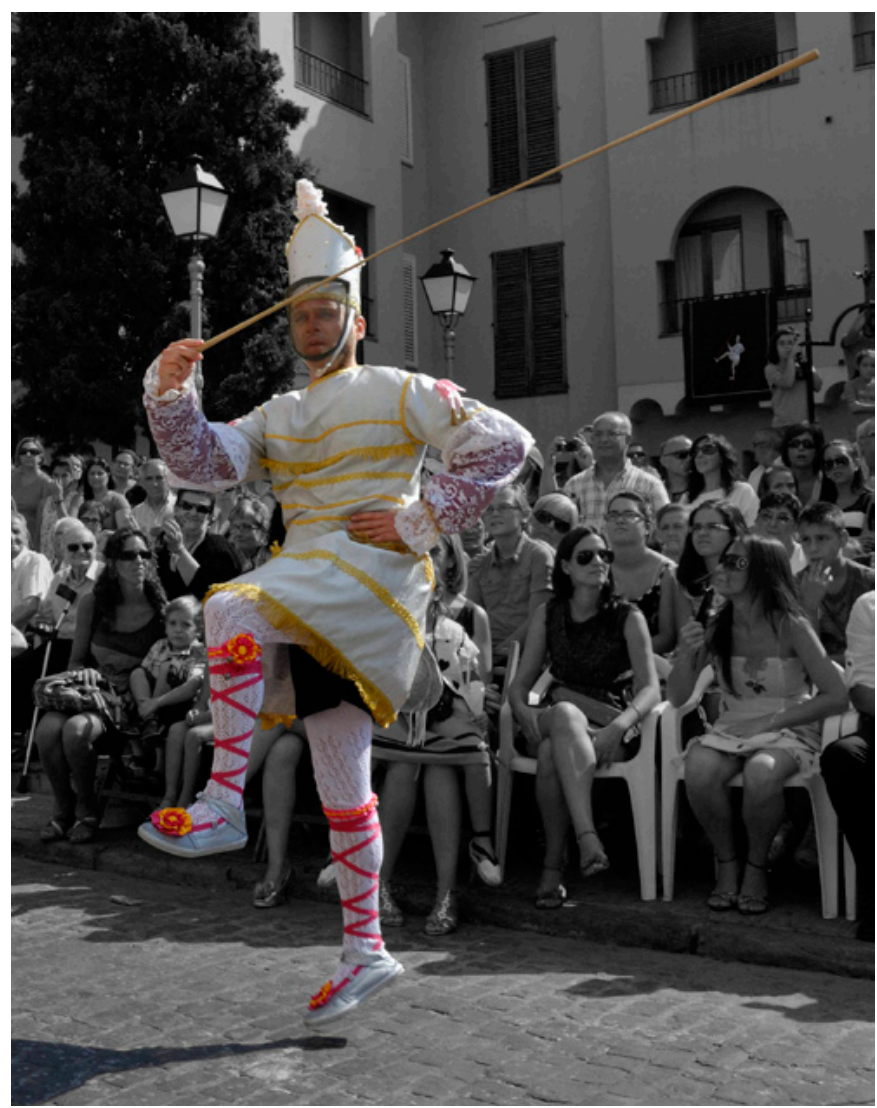

Fiestas de la Mare de Déu de la Salut en Algemesí (Valencia, España), inscrita en la Lista Representativa del Patrimonio Cultural Inmaterial | foto Juanjo Ripollés

56 de las Directrices Operativas de la Convención, ya que el hecho de que los Estados solicitantes no hayan podido cumplimentar en muchos de los casos los requerimientos formales para su acceso hace que se cuestione cuando menos su efectividad y se exija por tanto una orientación de dichos requerimientos.

El balance de la Convención durante estos 10 años es por tanto favorable pero mejorable por la posiblidad de desarrollar sus potencialidades en aras a la configuración de un patrimonio común de la humanidad; es decir, impulsar a través de la Convención un sentido positivo y humano de la globalización. 